\title{
Sobre o Secularismo Contemporâneo: Um Estudo de Caso Português No Período Democrático (Pós-1974)
}

\author{
Jorge Botelho Moniz ${ }^{1}$
}

\begin{abstract}
Resumo
O nosso artigo visa analisar as diferentes dimensões e os vários contornos do secularismo contemporâneo. Situamos o nosso marco teórico na perspetiva dos múltiplos secularismos de Alfred Stepan e das análises sensíveis aos diferentes contextos políticos, sociais e religiosos de Rajeev Bhargava. Para tal, delimitamos a nossa investigação às relações entre o Estado português e as igrejas e comunidades religiosas no período pós 1974. Ao examinarmos o seu padrão democrático de relação Estado-Igreja, nomeadamente através da observação dos mecanismos de apoio financeiro estabelecidos, procuramos entender em qual dos atuais modelos de secularismo Portugal se enquadra. O fato de este ser um estudo de caso controvertido, onde existe um modelo de separação com cooperação entre Estado e Igreja e, por consequência, um espírito de diálogo, negociação e de permanentes (re)definições do espaço público e simbólico de ambos, com particular destaque para uma religião específica, ajuda-nos a compreender o quão ambíguas e plásticas podem ser as fronteiras do secularismo moderno.
\end{abstract}

Palavras-chave: Portugal. Democracia. Múltiplos secularismos.

\section{About Contemporary Secularism: A Portuguese Case Study in A Democratic Period (Post-1974)}

\begin{abstract}
Our article addresses the different dimensions and the diverse shapes of contemporary secularism. Our theoretical framework derives from Alfred Stepan's

1 Doutorando em Ciência Política na Universidade Nova de Lisboa, Portugal. jobomoniz@ gmail.com
\end{abstract}


multiple secularisms perspective and Rajeev Bhargava's context-sensitive analysis of different political, social and religious environments. In order to do it, we circumscribe our research in the relations between the Portuguese state and the churches and religious communities in the post 1974 period. By examining its democratic pattern of state-church relations, namely through the analysis of the established mechanisms of financial support, we intend to understand in which of the current models of secularism Portugal fits in. The fact that this is a contested case study, where we find a model of separation with cooperation between State and church and, consequently, a spirit of dialogue, negotiation and of enduring (re) definitions of public and symbolic space of both of them, with special emphasis on one specific religion, certainly help us to comprehend how ambiguous and pliable the boundaries of modern secularism can be.

Keywords: Portugal. Democracy. Multiple secularisms.

\section{INTRODUÇÃo}

Em 1851, George Jacob Holyoake, um dos líderes do movimento racionalista inglês e fundador da Sociedade Secular, cunhou o termo secularismo. Com este vocábulo pretendeu descrever um movimento que oferecia, expressamente, uma teoria de organização social conduzida sem qualquer referência a uma teologia ou deidade. Apesar de Cady e Hurd (2010, p. 3) afirmarem que o termo, tal como o seu autor o havia construído, não é uma antítese da religião ou o lado de um binário secular-religioso; outros autores (Dobbelaere, 2004; Hurd, 2008; SWATOS; Christiano, 1999) defendem que ele pretende designar um movimento militante, de emancipação humana e política, comprometido com uma ordem mundial e com um programa de ação individual de solução dos problemas humanos, sem recorrer às irrelevantes explicações da igreja e da religião.

De acordo com Madan (1987, p. 748), o secularismo tinha sido construído dentro da "ideologia do progresso" e assumia a secularização como um processo positivo de lenta, mas irreversível, emancipação das esferas seculares face às religiosas. Com efeito, na sua obra Principles of Secularism (1854), Holyoake apela a esta distinção, defendendo a razão, a natureza e a experiência para se lograr uma 
melhor vida para a humanidade. Ou seja, com o recurso a esta palavra, não apenas o secular reafirma a sua superioridade de sentido relativamente à dimensão religiosa, como ainda passa a ser entendido como condição fundamental para o avanço da vida humana.

A relevância histórico-filosófica do conceito transformou-o, segundo Hurd (2008, p. 14-15), numa "categoria fundacional da modernidade política". Atualmente, o secularismo refere-se a um escopo de cosmovisões e doutrinas não religiosas que podem ser mantidas conscientemente ou elaboradas explicitamente em filosofias da história e projetos estatais ideológico-normativos, em projetos de modernidade e programas culturais. Alternativamente, pode ainda ser visto como um regime de conhecimento epistemológico ou assumirse, fenomenologicamente, como uma estrutura garantida (taken for granted) da realidade social moderna (CASANOVA, 2011, p. 55). Casanova, inspirado no trabalho de Taylor (2007), considera que este é um estágio de secularismo fenomenológico. Ou seja, uma etapa da era moderna na qual uma immanent frame das ordens cósmica, social, moral e política modernas opera como se o sagrado não existisse ou como se fosse contrário aos processos de amadurecimento, crescimento e emancipação humana (CASANOVA, 2011, p. 269).

Não obstante o peso negativo que lhe está associado normalmente, o secularismo político per se não assume, de forma obrigatória, qualquer desenvolvimento histórico progressivo que converterá a religião numa dimensão social insignificante. Ele é "na verdade, compatível com uma perspetiva positiva da religião" (CASANOVA, 2011, p. 69)2. Falamos, portanto, de um conceito contestado e ambíguo. Por um lado, refere-se a princípios de separação estrita da religião e política, justificados pela utilização de fundamentos

2 Contrariamente àquilo que entendemos como laicidade, onde se pressupõe que a dimensão pública da religião, quer por ação direta ou indireta do Estado, se torne menos expressiva. Não confundir com laicismo que corresponde a uma ação militante de promoção da redução da relevância pública das igrejas e comunidades religiosas e dos fenômenos religiosos. 
seculares ou de uma ética pública. Por outro lado, ele não é unilinear ou determinista. Reporta-se a diferentes tradições argumentativas e instituições e políticas concretas dentro das quais as contendas para regular a relação entre religião ${ }^{3}$ e política têm lugar, refletindo várias tradições e culturas políticas contextuais (Berg-Sørensen, 2013, p. 4).

Por este motivo, Casanova (2011, p. 54) afirma que repensar o secularismo nos obriga a manter em mente as distinções analíticas básicas entre o secular, como uma categoria epistêmica moderna central, a secularização, como uma conceitualização analítica de processos histórico-globais modernos, e o secularismo, como uma cosmovisão e doutrina.

No nosso ver, o secularismo é uma doutrina política que defende a separação entre religião e política a partir da perspetiva dos ideais políticos de liberdade e tolerância, igualdade e imparcialidade, neutralidade e universalidade; enquanto a secularização se refere aos processos históricos e sociais de racionalização, diferenciação funcional, privatização ou destradicionalização da religião e declínio das crenças religiosas ${ }^{4}$.

Estas distinções conceituais não são, na opinião de BergSørensen (2013), suficientes para se deixar de considerar o secularismo como um conceito contestado. Ele diz respeito, não somente a princípios de separação estrita da religião e política, justificados pela utilização de argumentos seculares ou de ética pública; mas, também, implica outras justificações discursivas, refletindo várias instituições e políticas concretas, que regulam a relação entre religião e política e

3 Visto que o presente artigo trata do secularismo - conceito que remete sobretudo para as relações Estado-Igreja - o termo religião e seus derivados, empregues ao longo do texto, devem ser entendidos nas suas dimensões organizacionais e institucionais. Perto do que Bourdieu, no seu "Genèse et structure du champ religieux", de 1971, denomina de campo religioso. Ou seja, uma esfera relativamente autónoma, caracterizada pela produção, reprodução e difusão de bens e serviços religiosos e, sobretudo, por um processo de complexificação institucional crescente.

4 Contudo, autores como Asad (2003) apontam para o fato de o objetivo normativo implícito do secularismo englobar teorias da secularização. 
reiteram várias tradições e culturas políticas contextuais. Por outras palavras, o significado de secularismo continua ambíguo e maleável.

Calhoun, Juergensmeyer e VanAntwerpen, na introdução do seu influente Rethinking Secularism, afirmam que uma forma de superar semelhantes ambiguidades epistemológicas é através da investigação das práticas seculares atualmente existentes. Neste sentido, propomos investigar as dimensões controvertidas do secularismo num país secularizado, religioso e católico como é o Portugal democrático do pós 25 de Abril de 1974. Na procura de ajustar os equilíbrios que sustentam a sua posição, o Estado português vem assumindo uma posição de separação com cooperação, com destaque para uma igreja, através da qual exalta a contínua necessidade de renovação da sua relação com a esfera religiosa que, pelas suas intricadas conexões, cabe às ciências sociais modernas investigar e interpretar.

\section{Múltiplas Modernidades e Múltiplos Secularismos}

Nos finais do século XX, Eisenstadt (2000), questionando as teorias clássicas da modernização e da convergência das sociedades industriais, introduz a expressão múltiplas modernidades. Para o autor, este conceito era a melhor forma de entender o mundo contemporâneo e de vê-lo como um processo de construção e reconstrução de uma multiplicidade de programas culturais (Eisenstadt, 2000, p. 2). As permanentes negociações dos múltiplos padrões institucionais e ideológicos da modernidade são levadas a cabo por atores sociais específicos, procurando diferentes programas de modernidade e estabelecendo diferentes visões sobre o que é uma sociedade moderna. Através da influência e do empenho destes atores com outros setores das suas sociedades, expressões únicas de modernidade podem ser realizadas. 
Segundo Ganzevoort (2014, p. 8), podemos concluir que em Eisenstadt o modo como as sociedades e as identidades modernas se constroem, pode variar entre países e entre diferentes períodos de tempo, podendo, mesmo dentro de uma determinada sociedade, apresentar contornos e modelos altamente diferenciados. Se juntarmos a religião a este quadro, o cenário fica ainda mais complexo. Para o autor, a modernidade trouxe novas formas de expressão religiosa (mais desinstitucionalizadas e fluidas) e novos atores a gerir o campo religioso (GANZEVOORT, 2014, p. 9). Isto trouxe novas formas de gestão do fenômeno religioso e das igrejas e comunidades religiosas por parte dos Estados. Um exemplo disso são os conceitos que os Estados liberais aplicam atualmente nas suas relações com o religioso: twin tolerantions (tolerâncias gêmeas) e principled distance (distância acordada). O primeiro estabelece os limites mínimos de liberdade de ação estabelecidos pelas instituições políticas, relativamente às autoridades e comunidades religiosas e vice-versa (STEPAN, 2000). O segundo estipula os limites da inclusão ou exclusão pública da religião e a medida na qual as autoridades estatais se empenham, ou não, nessa ação (BHARGAVA, 2011, p. 105-108). Por conta de semelhantes mudanças no paradigma das relações Estado-Igreja, o secularismo e o seu inerente princípio da separação devem ser repensados nas sociedades modernas, diz Ganzevoort (2014, p. 9).

Com efeito, o fato de vivermos "cada vez mais num mundo de modernidades múltiplas" (Taylor, 2007, p. 21), com reflexos nas relações entre as esferas temporal e espiritual, obriga-nos a pensar o secularismo moderno nas suas várias formas históricas; através de diferentes modelos normativos de separação legal-constitucional entre o poder público e a religião (CASANOVA, 2011, p. 55). É por este motivo que se deve falar dele no plural ${ }^{5}$ (CASANOVA, 2011; Stepan, 2011; Berg-Sørensen, 2013; Bhargava, 2013).

5 Esta tendência é também devedora das reflexões sobre os diferentes padrões de 
No campo da teoria, falar de secularismo no plural prova que a sua estrutura conceitual é controvertida. Ou seja, aqueles princípios guiadores que justificam a separação da religião e política - como já vimos, a liberdade e tolerância, igualdade e imparcialidade, neutralidade e universalidade - são pesados e hierarquizados diferentemente de uma versão de secularismo para outra. Isto significa que os secularismos são constituídos por uma pluralidade de configurações conceituais, embebidas em discursos políticos e abertas a modificação à luz de circunstâncias sociais e de discussões políticas em constante mutação. No campo empírico, reflete o modo como a relação entre religião e política se articula em contextos diferentes e sob circunstâncias divergentes. Melhor dizendo, evidenciar a pluralidade do secularismo ajuda a deslindar o modo como cada secularismo é estruturado nestes discursos públicos contextuais em termos de princípios políticos distintos e de suas justificações, expondo seus pontos de identificação e sentidos de pertença; bem como atestando as formas como é embebido em instituições e práticas políticas (nacionais) contextuais diferentes, regulando as relações religião-política; e como espelha as tradições culturais implícitas (Berg-Sørensen, 2013, p. 4).

Concordamos então com Bhargava (2011, p. 108-109) quando defende uma interpretação dos diferentes secularismos que seja sensível contextualmente (context-sensitive). Isto é, uma análise que capaz de captar a ideia de que a forma precisa e o conteúdo do secularismo variam, ou podem variar, de um contexto para outro e de um lugar para outro. Outra noção que vai ao encontro desta ideia é a de múltiplos secularismos. Com ela, Stepan (2011) pretende descrever as grandes variações e entender os principais modelos de relação EstadoIgreja existentes nas democracias modernas. Segundo o autor, podemse identificar quatro modelos de secularismo ou, como o autor explica:

secularização, desenvolvida por Martin (2005) ou por Casanova (2008); mas, também pela ideia de múltiplas secularidades de Wohlrab-Sahr e Burchardt (2012). 
"padrões democráticos de relação Estado, religião e sociedade" (Stepan, 2011, p. 114). Primeiro, ainda de acordo com este autor, está o modelo separatista (Stepan, 2011, p. 119-120), no qual o Estado exerce um controle muito reduzido sobre as religiões minoritárias ou maioritárias. Em segundo lugar, temos o modelo da religião estabelecida, característica dos países do Norte da Europa ou do Reino Unido, onde existem Igrejas de Estado (Stepan, 2011, p. 121-123). Em terceiro lugar, o modelo da acomodação positiva (Stepan, 2011, p. 123-125), um secularismo que estabelece as bases para um exercício governativo de intensa negociação e de indispensáveis partilhas de espaço (público ou simbólico) com as igrejas e confissões religiosas. Por fim, temos o modelo de respeito por todas as religiões, cooperação positiva e de distância acordada (Stepan, 2011, p. 126-139). Neste modelo, mais idealizado que os anteriores, o Estado coopera, estabelece acordos e respeita de forma igual todas as confissões religiosas, maioritárias ou minoritárias, nas esferas pública e privada. O caso mais aproximado deste modelo é o indiano.

Tanto o conceito de Bhargava como o de Stepan têm em comum a perspetiva de que, na resposta aos dissemelhantes desafios intelectuais e políticos colocados à secularidade dos Estados, devemos olhar além das construções teóricas de secularismo e examinar, preferencialmente, práticas estatais realmente existentes, derivando a partir delas uma conceção redesenhada de secularismo.

\section{Questões Históricas, Sociológicas e Jurídicas do Secularismo Português}

A fé cristã entra em Portugal no século II d.C. e, no contexto de pluralismo religioso que se vivia na época (com muçulmanos e judeus no território) vir-se-ia a afirmar, progressivamente, dentro da problemática da identidade religiosa como problema existencial. 
Em especial, no século XII com a expulsão dos muçulmanos, no século XV com a conversão forçada dos judeus e com o catolicismo triunfante, até às revoluções liberais de 1820. Por outro lado, derivado da sua posição geográfica, no extremo ocidental da Europa e apenas com uma fronteira terrestre, Portugal foi sempre um recetor tardio das mudanças que, ao nível cultural e mental, se iam produzindo no continente europeu, não experimentando, por exemplo, as ideias ou agitações da Reforma protestante (VIL AÇA, 1997, p. 277).

O catolicismo triunfante do século XV e, a partir de então, a ausência de experiências pluralistas religiosas no país marcaram, de forma indelével, o monolitismo religioso português. Atualmente, apesar da descida sentida no período posterior a Revolução de 1974, a percentagem de católicos em período democrático se estabilizou, encontrando-se hoje nos 81\% (MONIZ, 2016a, p. 196-197). O segundo maior grupo no campo religioso é, na verdade, aqueles que se definem pela ausência de uma crença definida: são os sem-religião (que reúnem estatisticamente crentes sem religião, ateus e agnósticos $)^{6}$. No total, eles representam $6,85 \%$ da população portuguesa (o que representou a subida de $42 \%$ deste contingente em relação a dados anteriores, considerando o período de 2001-2011 para o estabelecimento destes dados, cf. pode ser averiguado em Moniz (2016a, p. 197)). As restantes comunidades religiosas são, consequentemente, minoritárias, desafiando com pouca força o monolitismo católico (TEIXEIRA, 2012). Não obstante, a subida gradual desde a década de 1980 (36\% até 2011) dos grupos protestantes e das Testemunhas de Jeová, os seus números relacionais no escopo do campo religioso português são ainda residuais (3,9\% em 2011).

Estas referências sócio-históricas justificam que, do ponto de vista jurídico, existe uma longa tradição política em Portugal de

6 O fato de Portugal nunca ter experimentado uma visão religiosa moderada entre católicos e não-católicos (v.g. o protestantismo) repercute-se na ascensão deste grupo. 
relações com a Igreja católica, que podem ser atestados desde o ato de vassalagem de 1143, passando pelas onze concórdias do período 1210-1642 e seguindo até às inúmeras concordatas assinadas durante a formação do território, por exemplo (LEITE, 1993, p. 13-22). A falta de experiências pluralistas no campo religioso (v.g. protestantismo), tanto na corte como no povo, levou à abertura da primeira fresta na muralha legislativa nacional. Com a monarquia constitucional (18201910), o catolicismo passou a ser a religião oficial do Estado: o próprio artigo 25. da Constituição de 1822 afirma que "a religião da Nação Portuguesa é a católica apostólica romana". As três Constituições da monarquia liberal teriam, aliás, em comum a afirmação do catolicismo como religião oficial do Estado - art. 25 .. da Constituição de 1822; art.. 6. ․ da Constituição de 1826; e artigo 3. ${ }^{\circ}$ da Constituição de 1838 -, indo a Carta de 1826 um pouco mais longe no seu espírito ao afirmar, no n.. 4 do artigo 145., que "ninguém pode ser perseguido por motivos de Religião, uma vez que respeite a do Estado e não ofenda a Moral Pública". E assim seria até ao 5 de Outubro de 1910.

A proclamação da República foi acompanhada de um gravíssimo conflito religioso, ligado à reação contra o anterior sistema de união, derivado de um anticlericalismo difuso em certos setores da população urbana e do positivismo e jacobinismo do partido republicano. Não foi, portanto, de estranhar que a legislação dos primeiros meses do novo regime assumisse uma posição “vincadamente laicista e anticatólica" (MIRANDA, 1986, p. 120).

Neste sentido, foi publicado o decreto com força de lei de 20 de Abril de 1911 (Lei da Separação da Igreja e do Estado), no qual o artigo 2. - preceitua que "a religião católica apostólica romana deixa de ser a religião do Estado e todas as religiões são igualmente autorizadas". Para Leite (1993, p. 25), Afonso Costa, um dos impulsionadores desta lei, pretendia extinguir o catolicismo no país em poucas gerações. Assim, não só pela primeira vez o Estado e a Igreja aparecem dissociados, 
porquanto é eliminada a religião do Estado, como a religião católica surge em igualdade com as demais confissões, seja no que concerne ao culto particular ou ao próprio culto público ${ }^{7}$. Para Santos (2016, p. 503), este período inicia aquilo que designa por primeira separação entre Estado e Igreja em Portugal.

A Constituição de 1911 consagra ainda, no título respeitante aos direitos e garantias individuais (artigo 3. ${ }^{\circ}$, n.. 6 a 12 ; e artigo $4 .{ }^{\circ}$ ), na continuidade da Lei da Separação, a não-confessionalidade do Estado e a plena liberdade de consciência de todos os cidadãos.

Já durante o Estado Novo, a Constituição de 1933, no seu artigo 8. ${ }^{\circ}$, n. ${ }^{\circ}$, entre os direitos e garantias individuais dos cidadãos portugueses, menciona a liberdade e inviolabilidade de crenças e práticas religiosas, não podendo ninguém, por causa delas, ser perseguido, privado de um direito, ou isento de qualquer obrigação ou dever cívico, acrescentando também que ninguém seria obrigado a responder acerca da religião que professa. No título respeitante às relações do Estado com a Igreja católica e demais cultos, inscreviam-

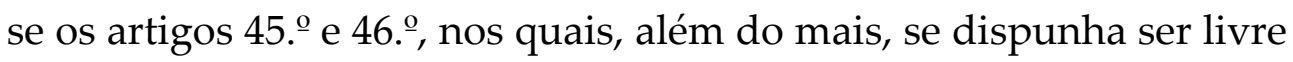
o culto público ou particular de todas as religiões, e ainda que, sem prejuízo do preceituado pelas concordatas, o Estado mantinha o regime de separação em relação à Igreja católica e a qualquer outra religião ou culto praticados dentro do território português. Este é o período da segunda separação, na sistematização de Santos (2016, p. 503-505). No entanto, em 7 de Maio de 1940, foi assinada a concordata entre a Santa Sé e a República Portuguesa, de cujas disposições mais significativas se verifica que houve, de um lado, o propósito de não voltar ao sistema da religião oficial do Estado; mas de outro, não se hesitou em reconhecer e garantir uma posição especial para a religião católica ${ }^{8}$.

\footnotetext{
7 Parecer da Câmara Corporativa publicado no "Boletim da Faculdade de Direito", Coimbra, vol. XVII, p. 334 ss. Citado por (Ac. TC 423/87, p. 4130).

8 Parecer da Câmara Corporativa publicado no "Boletim da Faculdade de Direito", Coimbra,
} 
Isto fica em evidência na revisão constitucional de 1951 onde, através da nova redação do artigo $45^{\circ}$, se considera o catolicismo como "a religião da Nação portuguesa". Apesar da permanência do princípio da separação na relação entre o Estado e a Igreja católica, o tratamento diferenciado à instituição coloca-a numa situação de supremacia face às outras confissões religiosas (MIRANDA, 1993, p. 78). De fato, durante este período, nomeadamente entre 1933 e 1971, as minorias religiosas tiveram dificuldades de representação formal ou simbólica com o poder político. Tanto a comunidade judaica (ultraminoritária no universo religioso português), como a protestante (discriminada em matéria de educação e ensino) e, dentro dela, a Testemunha de Jeová (perseguida e acusada de atuar contra a segurança estatal) ou a Federação Espírita Portuguesa (ilegalizada em 1953) foram afastadas ou não conseguiram fazer prevalecer os seus interesses no espaço público (SANTOS, 2016, p. 238-242).

Com a morte de Oliveira Salazar em 1968 e a ascensão de Marcelo Caetano surge uma nova fase do ordenamento da lei da liberdade religiosa em Portugal. A 21 de Agosto de 1971 é publicada a lei n.. $4 / 71$ que prevê um sistema de reconhecimento das confissões não católicas, inexistente até então (MIRANDA, 1993, p. 78-79). Na sua Base II, a lei afirma que o Estado não professa qualquer religião e que as suas relações com as confissões religiosas assentam no regime de separação, acrescentando que as confissões religiosas têm direito a igual tratamento, ressalvando as diferenças impostas pela sua diversa representatividade.

Com a queda do regime em 1974 e os inícios da democratização do país, a Constituição de 1976 vem garantir a liberdade religiosa sem acepção de confissões e sem quaisquer limites específicos. É, diz-nos Miranda (1986, p. 123), um estágio mais avançado do que os sucessivos regimes anteriores de união, de neutralidade laicista

vol. XVII, p. 359. Citado por (Ac. TC 423/87, p. 4130). 
e de relação preferencial com a Igreja católica, servindo a separação essencialmente de garantia da liberdade e da igualdade. É o período da terceira separação, segundo Santos (2016, p. 504). Cabe, enfim, fazer uma nota sobre a manutenção da Concordata de 1940 a seguir à Revolução de 25 de Abril de 1974.

A conservação do sistema concordatário no período democrático evidencia o temor estatal a respeito dos perigos inerentes a uma ruptura com a Igreja católica - "situações de vazio jurídico e prováveis novos confrontos entre a Igreja e o Estado" (Ac. TC 423/87, p. 4132). Este receio é revelado na frase do então Ministro dos Negócios Estrangeiros, Jaime Gama, no início das conversações sobre a concordata de 2004 entre o Governo português e a Santa Sé, onde afirma que "como limite, em caso de discordância sobre as negociações, manter-se-ia a Concordata de 1940" (GAMA, 2006, p. 9).

Com efeito, é expectável que esta fórmula de equilíbrio histórico entre a Igreja católica e o Estado português se mantenha. Segundo a jurisprudência, o fato concordatário é irrecusável, tem existência jurídica e os princípios essenciais que o inspiram achamse consagrados no tecido social e cultural do povo português por uma vivência de séculos, podendo dizer-se que, alguns deles, são indissociáveis da sua história, das suas tradições, da sua memória coletiva - por exemplo, os feriados católicos nacionais (Ac. TC 423/87, p. 4132).

Segundo Azevedo (2002, p. 14), a transição democrática e a Constituição de 1976 abriram portas a um novo Portugal. Todavia, as relações com a Igreja católica manter-se-iam idênticas (no plano formal). A vigência dos diplomas legais de 1940 seria apenas tocada pelo protocolo adicional de 1975, perdurando até ao século XXI quando a LLR - Lei da Liberdade Religiosa de 2001 conduz Estado e Igreja para uma nova concordata nascida em 2004. 


\section{O Secularismo à Portuguesa}

O modelo de cooperação entre público e religioso é o mais comum no contexto europeu (TORFS, 2007, p. 40-41). Nele o Estado reconhece o valor público da religião, existindo colaboração com as igrejas no sentido de alcançar fins sociais comuns. Em Portugal, este sistema é uma marca indelével das relações Estado-Igreja(s) (TORFS, 2007, p. 38) e, por consequência, corresponde ao ponto de partida do qual inauguramos a nossa análise sobre o secularismo.

São três os mais importantes documentos que regulam, atualmente, as relações Estado-Igreja em Portugal. Por ordem cronológica: a Constituição de 1976, a LLR de 2001 e a Concordata de 2004. Transversal a todos eles é a questão da separação de poderes e da não-confessionalidade do Estado (n. 4 do artigo 41. da Constituição, artigos 3.ํ e 4.ำ da LLR e preâmbulo da Concordata). Portugal é, portanto, aquilo a que constitucionalmente se designa por Estado com "separação absoluta" (MIRANDA, 1993, p. 355-56), i.e., um estágio evoluído de neutralidade secular, que garante a igualdade de todas as confissões religiosas e que não sofre, formalmente, influência ou controle por parte de qualquer uma delas.

Isso não significa, porém, que a sua condição seja irreligiosa. Pelo contrário, um Estado como o português não pretende impor crenças ou instituições ateístas. Ou seja, não apoiando nem se opondo a qualquer confissão, protege o direito de todos os cidadãos a manter as suas próprias crenças - religiosas, não-religiosas ou até antirreligiosas. OEstado português, por permitir a criação de espaços de sociabilidadee de manifestação da consciência individual livres da autoridade clerical (o que não significa a exclusão dos contributos religiosos), pode ser entendido como um Estado pró-secularismo, diferente, pois, de prólaicização, que resultaria da transformação dessa reclamação setorial 
e parcial em modelo de sociedade - forçosamente não-confessional universal, obrigatório e garantido pela autoridade política.

Como explicam Miranda e Medeiros (2010, p. 912), o facto de o Estado não assumir fins religiosos, não professar nenhuma religião, nem submeter qualquer Igreja a um regime administrativo, não significa a irrelevância do fato religioso ou não cooperação, quando possível ou conveniente, para o bem-comum. Se, por um lado, a separação e a não-confessionalidade envolvem a neutralidade religiosa do Estado, por outro, já não implicam o seu desconhecimento do fato religioso enquanto fato social (Ac. TC 423/87, p. 4137). As posturas de aconfessionalidade e separação não implicam que ele não possa colaborar com as igrejas e comunidades religiosas. Antes, pelo contrário, o princípio da separação requer do Estado não uma pura atitude omissiva, uma abstenção ou um non facere, mas um facere, traduzido no dever de dinamizar os valores e interesses socialmente legítimos e assegurar ou propiciar o exercício da religião (Ac. TC 174/93).

O Estado assume, nesta recomposição do religioso na sociedade, um espírito de separação com cooperação (Alves, 2007; Miranda, 2007), com particular destaque para a Igreja católica, em relação à qual Portugal é, jurídica e institucionalmente, um país de regime concordatário (Lopes, 2002, p. 73). Para Jardim (2007, p. 52), esta fórmula corresponde ao reconhecimento da sua relevância histórica e cultural na sociedade portuguesa; a sua natureza e missão e o seu ordenamento jurídico e o valor social da sua intervenção.

Assim sendo, apesar de o Estado não ser confessional e haver uma separação formal entre as duas esferas, ele coopera com as igrejas e comunidades religiosas radicadas em Portugal, tendo em vista, por exemplo, a promoção dos direitos humanos, da paz ou da liberdade religiosa. É, de certa forma, aquilo que Stepan (2000, p. 37) chama de twin tolerantions. Ou seja, um estágio de separação entre as esferas 
política e religiosa, mas onde existe uma relação amigável ou positiva entre ambas (STEPAN, 2000, p. 42).

No concernente à tipologia de relação Estado-Igreja, Portugal está próximo daquilo que Bhargava (2011, p. 105-108) designa por distância acordada (principled distance), na medida em que lhe é permitido um tratamento diferenciado das várias igrejas e confissões religiosas. Esta tipologia é baseada na separação com lei especial, hierarquização de igrejas e liberdade religiosa (MATOS, 2013, p. 93100).

Para compreender este modelo devemos analisá-lo à luz do esforço de regulamentação estatal das igrejas, por meio de uma ou mais leis especiais-por exemplo, as concordatas, as leis de liberdade religiosa ou acordos formais com as confissões religiosas. A sua característica essencial é a existência de um registo estatal obrigatório que decorre de uma lei especial ou de um ato normativo de valor equivalente. Este tipo de regime pode ser desdobrado em duas subcategorias: uma trata todas as igrejas por igual e a outra hierarquiza-as. A primeira parece prevenir a introdução de um princípio discriminatório entre igrejas, enquanto a segunda, de acordo com Matos (2013, p. 68), se encontra "metaforicamente a caminho da Igreja de Estado". A separação com hierarquização de igrejas é, então, uma variante da separação à francesa, na qual a lei estatal dispõe de modo a singularizar uma ou várias igrejas. O Estado passa a gerir a sua própria ordem simbólica, conferindo distinções positivas e negativas às diferentes igrejas e comunidades religiosas.

No país podemos detetar, grosso modo, quatro escalões de hierarquização. No cume da pirâmide, pese embora não formalmente (CANAS, 2008, p. 478-485), situa-se a Igreja católica por consequência da relação concordatária. Abaixo encontramos as confissões religiosas que concluíram acordos com o Estado. É o caso das igrejas radicadas historicamente em Portugal - a aliança evangélica e as comunidades 
islâmica e israelita). Em terceiro lugar os cultos registrados, mas sem acordo especial ${ }^{9}$. Por fim, as igrejas e confissões religiosas sem personalidade jurídica, por consequência da ausência de registo. Com base nestes elementos, desde que se obedeça ao princípio de fato (critérios de representatividade ou longevidade), as autoridades públicas passam a estar legitimamente autorizadas a tratar de maneira distinta as diferentes igrejas.

Assim sendo, em Portugal, o sistema de relações Estado-Igreja implementado pela Constituição de 1976 assume a neutralidade, a igualdade de tratamento e a separação entre o Estado e confissões religiosas. O diploma não refere qualquer forma de diálogo contratual entre Estado e igrejas, nem invoca qualquer religião particular (BRITO, 2006, p. 155). Contudo, como diz Canas (2008, p. 477), o princípio da igualdade não é completamente aplicado e o da separação deve ser interpretado de maneira muito reservada. Se, por um lado, a LLR foi um passo importante rumo à igualdade de tratamento, permitindo às confissões religiosas estabelecer acordos com o Estado em matérias de interesse comum; por outro, a mesma lei não só não incentiva nem favorece estes acordos, como ainda estabelece um lugar privilegiado para a Igreja católica (artigo 58ㅜ), mantendo a força das concordatas de 1940 e 2004 (BRITO, 2006, p. 163-164). Vários autores defendem que esta aparente situação de desigualdade se encontra, de fato, em consonância com o princípio do tratamento igual face à importância social da Igreja católica em Portugal. Ou seja, ela deve ser interpretada à luz do seguinte preceito legal: tratar o igual como igual e o desigual como desigual.

O direito português estabelece, como vimos, uma hierarquização entre igrejas e cultos. No cume, as igrejas e cultos instalados à longa data ou radicados no país ${ }^{10}$ - com particular

9 Em 2013 eram mais de 730, um aumento de 11\% face a 2010 (MONIZ, 2016a, p. 206).

10 Os critérios para serem considerados como radicados em Portugal são: estar há 30 anos, de forma organizada, no país ou há 60 anos no estrangeiro e, pelo número de membros e pela 
destaque para a Igreja católica, por conta do estatuto particular conferido pelo tratado internacional concordatário ${ }^{11}$. A sua posição de destaque não é meramente instrumental. Pelo contrário, como veremos posteriormente, ela confere direitos particulares, como, por exemplo, a validade civil do casamento religioso, o reembolso do IVA, a perceção de $0,5 \%$ dos rendimentos dos contribuintes, acesso ao tempo de antena na televisão e rádio públicas, ou possibilidade de assegurar cursos de religião e moral nas escolas públicas.

\section{UM SECULARISMO CATÓLICO?}

O fato de o Estado português não assumir fins religiosos, não professar nenhuma religião nem submeter as instituições religiosas a qualquer regime administrativo, não significa a irrelevância do religioso ou a não-cooperação, quando possível ou conveniente, para o bem-comum. Como vimos, o princípio da separação requer do Estado não uma pura atitude omissiva, mas um secularismo positivo traduzido no dever de dinamizar os valores e interesses socialmente legítimos e assegurar ou propiciar o exercício da religião.

Segundo Fox (2015, p. 84, 90), o tipo mais comum e mais relevante de secularismo positivo atualmente existente é o financiamento das igrejas e confissões religiosas. A sua tangibilidade, associada à maior exposição e controle estatal que as instituições religiosas passam a sofrer (FOX, 2015, p. 85), tornam-na num lugar de destaque para se analisarem os contornos do secularismo moderno.

Por exemplo, em matéria de educação e ensino, não obstante a Constituição de 1976 estabeleça que o ensino público não deva ser

sua história em Portugal, ser expectável que a sua estrutura perdure (CANAS, 2008, p. 483).

11 A própria aquisição de estatuto de pessoa jurídica moral é garantida de maneira diferente, visto que a Igreja católica e os demais cultos se encontram sujeitos a regimes jurídicos diferentes. O estatuto da Igreja é reconhecido pela assinatura duma convenção de direito internacional e o das outras igrejas através do registo de cultos criado pelo decreto-lei $134 / 2003$. 
confessional (43\%/3), o Estado garante a liberdade de ensino de qualquer religião, desde que praticada no contexto da respetiva confissão (41\%/4). Nas escolas públicas, até ao ensino secundário, o Estado paga uma retribuição aos mais de 1.000 professores de educação moral e religiosa existentes no país (BRITO, 2009, p. 290). São três as comunidades que beneficiam deste apoio: primeira e destacadamente, a Igreja católica, depois a aliança evangélica e a comunidade bahá'í (BRITO, 2009, p. 290-91)12. Os professores de moral evangélica, contrariamente aos seus homólogos católicos, não são equiparados a funcionários públicos e, como tal, são trabalhadores pagos à hora (BRITO, 2009, p. 291). Ainda neste contexto, segundo Sousa e Brito (BRITO, 2009, p. 294), nenhum financiamento ao ensino superior é permitido, salvo no caso da UCP - Universidade Católica Portuguesa. No decreto-lei 307/71, revisto pelo decreto-lei 128/90, vem previsto que UCP pode ser apoiada pelo Estado e que esse apoio pode revestir a forma de contribuições financeiras. Este auxílio deve-se ao facto de a UCP não ser considerada como uma universidade privada, porquanto ela possui o estatuto de pessoa coletiva de utilidade pública.

No que concerne a assistência social, uma nota deve ser feita sobre as IPSS - Instituições Particulares de Solidariedade Social. Segundo a norma XXII do despacho normativo 75/92, na prossecução dos seus objetivos de solidariedade social, as IPSS têm direito a comparticipação pública. Para tanto são estabelecidos acordos e protocolos de cooperação entre estas pessoas coletivas de utilidade pública e o $E \operatorname{stado}^{13}$. Por diversos motivos históricos, políticos e culturais uma das maiores beneficiárias é a Igreja católica - que tem em sua posse $75 \%$ da rede de intervenção social (MONIZ, 2014, p.

12 Enquanto a Igreja católica tem cerca de 250.000 alunos inscritos na disciplina de Educação Moral e Religiosa católica, a aliança evangélica apenas conta com 2.000. A religião bahá'í conta com números muito pouco expressivos (MONIZ, 2016b, p. 91).

13 Cf. Artigo $8^{\circ}$ do decreto-lei 119/83 sobre os estatutos das IPSS e o no 3 do artigo $31^{\circ}$ da lei $4 / 2007$, sobre as bases gerais do sistema de segurança social. 
223-256). Dentre os milhares de instituições existentes, mais de 1.400 pertencem-lhe (cerca de 30\% do total) direta ou indiretamente (MAIA, 2012). Contudo, as instituições de solidariedade, com estatuto de IPSS, de qualquer confissão religiosa podem subvencionadas pelo Estado (BRITO, 2009, p. 290). De acordo com o Pe. Lino Maia (2012), em 2012, $42 \%$ do Orçamento de Estado na rubrica de ação social foi destinado às IPSS (MAIA, 2012, p. 3).

No campo dos meios de comunicação de massa, o caso português, oferece financiamento público de emissões religiosas televisivas e radiodifundidas. Este direito está previsto para a prossecução dos fins religiosos de todas as igrejas e comunidades religiosas inscritas (artigo 25\%/1 da LLR). Apesar da universalidade do preceito legal, o n 2 do artigo 25ำ dispõe que atribuição e distribuição do tempo de emissão devem ter lugar mediante a representatividade das confissões. Daí o predomínio da religião católica, por exemplo, em programas televisivos como "Caminhos" e "A Fé dos Homens" e a sua exclusividade de conteúdos teledifundidos em programas como o "70x7", além das eucaristias dominicais.

Em matéria fiscal, os artigos $31^{\circ}$ e $32^{\circ}$ da LLR de 2001 estabelecem inúmeras isenções que favorecem as igrejas e comunidades religiosas inscritas em Portugal, dependendo do seu estatuto jurídico no país. Tal como os conceitos de lei especial e de hierarquização de igrejas denunciam, existe uma estrutura de benefícios fiscais em três níveis: na base, os que se aplicam a todas as confissões religiosas, qualquer que seja o seu estatuto jurídico; no meio, as que respeitam as pessoas jurídicas religiosas registadas enquanto tal; no cume, as igrejas e cultos radicados no país que gozam de todos os benefícios fiscais previstos no artigo $26^{\circ}$ da concordata de 2004 . Esta esquematização beneficia largamente a Igreja católica e as demais igrejas com o estatuto de radicadas no país, nomeadamente no que respeita o IVA - imposto sobre o valor acrescentado, as taxas contributivas para a segurança 
social sobre os rendimentos auferidos pelos seus empregadores e trabalhadores, as deduções à coleta e as majorações sobre a doações ou ainda a consignação fiscal, ou seja, a quota de $0,5 \%$ do imposto renda que as pessoas singulares podem destinar às instituições religiosas radicadas no país, para a prossecução dos seus fins religiosos ou de beneficência (MONIZ, 2016b, p. 90-103).

Ora, uma tal situação evidencia, sobretudo, a capacidade da Igreja católica para influenciar políticas e práticas públicas e a tendência do Estado português, mediante critérios de objetividade, necessidade e adequação (MIRANDA, 2007, p. 106) para compromissos políticos católicos, i.e., para a prossecução de uma sincera e leal cooperação entre o Estado e a Igreja católica (GAMA, 2006, p. 11). De acordo com a formulação de Chaplin (2008, p. 20-28), uma semelhante capacidade de influência pública de uma igreja ou comunidade religiosa sobre o poder político e, por consequência, a propensão do Estado para, quer intencionalmente quer não, estabelecer compromissos políticos que beneficiem, neste caso, a Igreja católica, fazem deste um caso de secularismo católico.

Assim sendo, a necessidade do Estado assumir o princípio da separação, a indispensabilidade de afastar o peso e a influência da religião da sua esfera e a não circunscrição do religioso aos cuidados paroquiais locais, manifestam um equilíbrio delicado no caso português. Para certos autores nacionais, este encadeamento argumentativo reflete o legado laicista da primeira República - o “complexo Afonso Costa" (CATROGA, 2006, p. 368) - que, além de ter promovido uma relação pacificada entre Igreja, Estado e sociedade, conduziu uma tendência para o silenciamento nas suas relações. Em outras palavras, mesmo sob a possibilidade de inconstitucionalidade de certas disposições e práticas, elas são consideradas de menor importância perante o receio de causar perturbações e de fazer surgir uma nova questão religiosa no país. 
Todavia, o reconhecimento por parte da República portuguesa quanto à natureza e missão da Igreja na sociedade não envolve um regresso religioso ao passado (ALVES, 2007, p. 35) nem, tampouco, uma dissolução do atual modelo de secularismo. Ele significa, antes, a necessidade de aceitação duma separação saudável ou positiva, na qual se aprimora e aprofunda a relação dialógica, de pacto e entendimento entre Estado, Igreja e sociedade.

Uma tal necessidade de segurar os dois lados da corda - por um lado, aceitar que a identidade católica continue a desempenhar um papel relevante na sociedade portuguesa (CARVALHO, 2003; TEIXEIRA, 2012) e, por outro, valorizar e continuar a defender o princípio da separação - traduz-se nas aparentemente dicotômicas "separação laica não absoluta" (VILAÇA, 2006, p. 376), "quase laicidade" (CATROGA, 2006, p. 370) ou "laicidade colaboracionista" (MANUEL; MOTT, 2006 p. 56), típicas dos períodos democráticos contemporâneos dos países do Sul da Europa e fortemente visíveis em Portugal.

\section{Conclusão}

Tal como o estudo do caso português desvendou, o secularismo é compatível com uma perspetiva positiva da religião. No entanto, devemos notar que os modelos (positivos ou negativos) de secularismo não são fórmulas normativas estanques. Antes, são arranjos conjunturais e políticos socialmente construídos. No caso português, esta situação é visível principalmente a partir de 1976, com a transição democrática. Mas, estendeu-se até ao século XXI, com os exemplos flagrantes da LLR de 2001 e da concordata de 2004.

Pela sua constante disputa entre os princípios de separação e de cooperação, pelo seu um espírito de diálogo, negociação e de permanentes (re)definições do espaço público e simbólico de ambos, o 
modelo de secularismo democrático lusitano afigura-se-nos como de acomodação positiva.

Esta acomodação é positiva - no sentido das tolerâncias gêmeas de Stepan -, porque obriga o Estado a apoiar ativamente a religião e a promover o seu lugar na sociedade. Esta ideia de promoção de uma relação amigável e pacífica entre Estado-Igreja, compatível com o princípio da separação, é predominante não apenas nos discursos oficiais, mas também na aplicação da lei pelos tribunais e pelos governantes públicos. Sintomáticos são os casos dos acórdãos do Tribunal Constitucional português, da legislação nacional (constitucional e subconstitucional) ou do auxílio financeiro (direto ou indireto) do Estado às igrejas e comunidades religiosas.

Neste contexto, a palavra acomodação - no sentido da distância acordada de Bhargava - é igualmente relevante, porquanto demonstra a extensão da discriminação (seja positiva ou não) do Estado relativamente às igrejas e comunidades religiosas radicadas no país. Tal como na questão do financiamento supracitada, o Estado acomoda as religiões quando as ajuda a coletar impostos. Com esta arrecadação tributária o poder social das igrejas não é apenas acomodado, mas também é reforçado pelo poder público, porque é o próprio Estado que impõe os critérios da inclusão ou exclusão da religião desse e doutros benefícios. Dado que, em Portugal, se vem garantindo um tratamento especializado à Igreja católica, esta é a instituição religiosa que mais se beneficia com esta acomodação.

Se, por um lado, no país, este modelo de secularismo de separação com cooperação tem contribuído para a acomodação das minorias religiosas (nomeadamente após a promulgação da LLR); por outro lado, esta dinâmica acomodatícia, que permite ao Estado gerir a sua própria ordem simbólica, conferindo distinções positivas e negativas às diferentes igrejas e comunidades religiosas, parecenos tender a derivar, metaforicamente ou não, para um modelo de 
secularismo de religião estabelecida. O registo público obrigatório das igrejas e comunidades religiosas, o sistema de lei especial (incluindo a exceção concordatária) e a hierarquização de igrejas, além dos benefícios que daí advêm e o princípio da separação com cooperação (com o tratamento especializado a uma igreja), permitem não só que o próprio Estado estabeleça distinções positivas e negativas entre as diferentes igrejas e comunidades religiosas; mas, também legitimam a organização da sua ordem simbólica e o destaque dado à Igreja católica no seio do universo religioso português.

Com efeito, as várias dimensões do secularismo não são geométricas. Elas são consequência de arranjos institucionais socialmente construídos e são um reflexo das vicissitudes históricas e das ambições político-sociais contextuais. Dentro desta linha, o Estado português parece assumir um tipo de secularismo dialógico e de compromisso entre a doutrina (secular) que preconiza e a crença (católica) das pessoas que governa, reconhecendo que apesar de o Estado estar, formalmente, separado da religião a sociedade não está.

\section{REFERÊNCIAS}

ALVES, D. João. Revisão da concordata de 1940: algumas notas. In: GOMES, M. S. C. (Coord.). Estudos sobre a nova concordata: Santa Sé - República Portuguesa, 18 de maio de 2004. Lisboa: Universidade Católica, 2007. p. 29-37. (Lusitania Canónica, $11)$.

ASAD, Talal. Formations of the secular: christianity, islam, modernity. Stanford: Stanford University Press, 2003.

AZEVEDO, Carlos Moreira. Momentos e temas em confronto nas relações igrejaestado em Portugal. In: GOMES, Manuel Saturnino Costa (Coord.). Relações igrejaestado em Portugal: desde a vigência da concordata de 1940. Actas das X Jornadas de Direito Canónico. Lisboa: Universidade Católica, 2002. p. 9-30. (Lusitania Canónica, 8),

Berg-Sørensen, Anders. Introduction: contesting secularism. In: BERG-SØRENSEN, Anders (Ed.). Contesting secularism: comparative perspectives. Nova Iorque: Routledge, 2013. 
BHARGAVA, Rajeev. Multiple secularism and multiple secular states. In: BERGSØRENSEN, Anders (Ed.). Contesting secularism: comparative perspectives. Nova Iorque: Routledge, 2013.

BHARGAVA, Rajeev. Rehabilitating secularism. In: CALHOUN, Craig; JUERGENSMEYER, Mark; VAN ANTWERPEN, Jonathan (Ed.). Rethinking secularism. Nova Iorque: Oxford University Press, 2011. p. ini-fin.

BRITO, José de Sousa. Convenantal and non-convenantal cooperation between state and religion in Portugal. In: PUZA, R.; DOE, N. (Ed.). Religion and law in dialogue: convenantal and nonconvenantal cooperation between state and religion in europe. Proceedings of the Conference Tubingen. Dudley: Peeters, 2006. p. 155164.

BRITO, José de Sousa. Le financement des communautés religieuses au Portugal. In: BASDEVANT-GAUDEMET, B.; BERLINGÒ, S. (Ed.). The financing of religious communities in the European Union. Trier: Institute for European Constitutional Law, 2009. p. 287-294.

CADY, Linell; HURD, Elizabeth Shakman. Comparative secularism and the politics of modernity: an introduction. In: CADY, Linell E.; HURD, Elizabeth Shakman (Ed.). Comparative secularism in a global age. Nova Iorque: Palgrave Macmillan, 2010. p. 3-24.

CANAS, Vitalino. État et églises au Portugal. In: ROBBERS, Gerhard (Ed.). État et églises dans l'union europeenne. 2. ed. Trier: Institute for European Constitutional Law, 2008. p. 470-500.

CARVALHO, António. As igrejas e o estado em Portugal. In: CARVALHO, António (Coord.). Actas dos IX cursos internacionais de verão de Cascais. Cascais: Câmara Municipal de Cascais, 2003. v. 3.

CASANOVA, José. Public religions revisited. In: VRIES, Hent (Ed.). Religion: beyond a concept. Nova Iorque: Fordham University Press, 2008. p. 101-119.

CASANOVA, José. The secular, secularizations, secularisms. In: CALHOUN, Craig; JUERGENSMEYER, Mark; VAN ANTWERPEN, Jonathan (Ed.). Rethinking secularism. Nova Iorque: Oxford University Press, 2011. p. 54-74.

CATROGA, Fernando. Entre deuses e césares: secularização, laicidade e religião civil. Coimbra: Almedina, 2006.

CHAPLIN, Jonathan. Talking god: the legitimacy of religious public reasoning. Londres: Theos, 2008.

DOBBELAERE, Karel. Secularization an analysis at three levels. 2. ed. Bruxelas: PIE Peter Lang, 2004. 
EISENSTADT, Shmuel. Multiple modernities. Daedalus, Cambridge, v. 129, n. 1, p. $1-30,2000$.

FOX, Jonathan. Political secularism, religion and the state: a time series analysis of worldwide data. Cambridge: Cambridge University Press, 2015.

GAMA, Jaime. Prefácio. In: UNIVERSIDADE CATÓLICA PORTUGUESA. Estudos sobre a nova concordata. Lisboa, 2006. Disponível em: <http://www.uceditora.ucp.pt/ resources/Documentos/UCEditora/Indices/2008/ESTUDOS\%20SOBRE\%20A\%20 NOVA\%20CONCORDATA.pdf $>$. Acesso em: 12 jul. 2016.

GANZEVOORT, Ruard. Preface. In: TOPIĆ, Martina SREMAC, Sremac. (Ed.). Europe as a multiple modernity: multiplicity of religious identities and belonging. Cambridge: Cambridge Scholars Publishing, 2014, p. 8-10.

HURD, Elizabeth Shakman. The politics of secularism in international relations. Nova Jérsia: Princeton University Press, 2008.

JARDIM, José Vera. Uma concordata do concílio e do estado democrático. In: GOMES, M. S. C. (Coord.), Estudos sobre a nova concordata: Santa Sé - República Portuguesa, 18 de maio de 2004. Lisboa: Universidade Católica, 2007. p. 49-57. (Lusitania Canónica, 11),

LEITE, António. Acordos entre a Santa Sé e Portugal anteriores à concordata de 1940. In: UNIVERSIDADE CATÓLICA PORTUGUESA (Ed.). A concordata de 1940, Portugal - Santa Sé. Lisboa: Edições Didaskalia, 1993. p. 11-27. (Fundamenta, 10).

LOPES, José Almeida. A concordata de 1940 entre Portugal e a Santa Sé na lei da liberdade religiosa de 2001. In: GOMES, M. S. C. (Coord.). Relações igreja-estado em Portugal: desde a vigência da concordata de 1940. Lisboa: Universidade Católica, 2002. p. 57-112. (Lusitania Canónica, 8).

MADAN, Triloki Nath. Secularism in its place. The Journal of Asian Studies, Cambridge, v. 46, n. 4, p. 747-759, 1987.

MAIA, Lino. Caridade e solidariedade, papel dos cristãos numa sociedade mais solidária. In: CONFERÊNCIA NACIONAL DAS INSTITUIÇÕES DE SOLIDARIEDADE, SEMANA SOCIAL: ESTADO SOCIAL E SOCIEDADE SOLIDÁRIA, 2012, Porto. Anais... Porto, 2012. Disponível em: <http://novo.cnis. pt/>. Acesso em: 12 jul. 2016.

MANUEL, Paul Christopher; MOTT, Manuel. The latin european church: "une messe est possible". In: MANUEL, Paul Christopher; REARDON, Lawrence C.; WILCOX, Clyde (Ed.). The catholic church and the nation-state. Washington: Georgetown University Press, 2006. p. 53-68. 
MARTIN, David. On secularization: toward a revised general theory. Burlington: Ashgate, 2005.

MATOS, Luís Salgado. Para uma tipologia do relacionamento entre o estado e a igreja". In: FERREIRA, António Matos; MATOS, Luís Salgado (Org.). Interações do estado e das igrejas: homens e instituições. Lisboa: Imprensa de Ciências Sociais, 2013. p. 25-106.

MIRANDA, Jorge. A concordata e a ordem constitucional portuguesa. In: UNIVERSIDADE CATÓLICA PORTUGUESA (Ed.). A concordata de 1940, Portugal Santa Sé. Lisboa: Edições Didaskalia, 1993. p. 67-84. (Fundamenta, 10).

MIRANDA, Jorge. A constituição e a concordata: brevíssima nota. In: GOMES, M. S. C. (Coord.). Estudos sobre a nova concordata: Santa Sé - República Portuguesa, 18 de maio de 2004. Lisboa: Universidade Católica, 2007. p. 101-112. (Lusitania Canónica, $11)$.

MIRANDA, Jorge. Liberdade religiosa, igrejas e estado em Portugal. Nação e Defesa, Potugal, ano 11, n. 39, p. 119-136, 1986.

MIRANDA, Jorge; MEDEIROS, Rui. Constituição Portuguesa Anotada, Tomo I: introdução geral e preâmbulo, artigos $1^{\circ}$ a $79^{\circ}$. 2. ed. Coimbra: Wolters Kluwer; Coimbra Editora, 2010.

MONIZ, Jorge Botelho. A secularização na ultramodernidade católica européia: uma proposta de análise contextual e multidimensional do fenômeno da secularização. Em Tese, Florianópolis, v. 13, n. 1, p. 188-219, 2016 a.

MONIZ, Jorge Botelho. Igreja católica e caridade em Portugal. Do múnus bíblico de ajudar o "outro" à sua indispensabilidade no século XX. Revista Brasileira de História das Religiões, Maringá, v. 7, n. 19, p. 223-256, 2014.

MONIZ, Jorge Botelho. O financiamento público da religião na Europa católica pós-crise. Ius Ecclesiae, Pisa, v. 28, n. 1, p. 79-112, $2016 \mathrm{~b}$.

TEPAN, Alfred. Religion, democracy and the "twin tolerations". Journal of Democracy, Baltimore, v. 11, n. 4, p. 37-57, 2000.

SANTOS, Paula Borges. A Segunda separação: a política religiosa do Estado Novo (1933-1974). Coimbra: Edições Almedina, 2016.

STEPAN, Alfred. The multiple secularisms of democratic and non-democratic regimes. In: CALHOUN, Craig; JUERGENSMEYER, Mark; VAN ANTWERPEN, Jonathan (Ed.). Rethinking secularism. Nova Iorque: Oxford University Press, 2011. p. 114-144. 
SWATOS, William; CHRISTIANO, Kevin. Secularization theory: the course of a concept. Sociology of Religion, Washington, v. 60, n. 3, p. 209-228, 1999.

TAYLOR, Charles. A secular age. Massachusetts: The Belknap Press of Harvard University Press, 2007.

TEIXEIRA, Alfredo. Identidades religiosas em Portugal: representações, valores e práticas. 2012. Disponível em: <http://www.udip.porto.ucp.pt/sites/default/files/ files/UDIP/ Documentos/Sondagem_Abril\%202012.pdf>. Acesso em: 8 dez. 2016.

TORFS, Rik. Religion and state relationships in europe. Religious Studies Review, Malden, v. 1, n. 4, p. 31-41, 2007.

VILAÇA, Helena. Alguns traços acerca da realidade numérica das minorias religiosas em Portugal, Lusotopie 1999, Paris, p. 277-289, 1997.

VILAÇA, Helena. Da torre de babel às terras prometidas: pluralismo religioso em Portugal. Porto: Edições Afrontamento, 2006. (Coleção Biblioteca das Ciências Sociais).

WOHLRAB-SAHR, Monika; BUCHARDT, Marian, "Multiples Secularities: toward a cultural sociology of secular modernities". Comparative Sociology, Toronto, v. 11, p. 875-909, 2012. 